\section{Estudo experimental sobre a intoxicação de Gallus gallus domesticus com sementes de Crotalaria spectabilis. I - Efeito em aves na fase inicial de crescimento}

\author{
Experimental study on the intoxication of Gallus gallus domesticus \\ with Crotalaria spectabilis seeds. I - Effect in broiler during the initial \\ fase of growing
}

\author{
Mario Roberto HATAYDE'; Angelo BERCHIERI-JUNIOR²; Antonio Carlos ALESSI²; Sandra \\ Mara CURTARELIL ${ }^{3}$
}

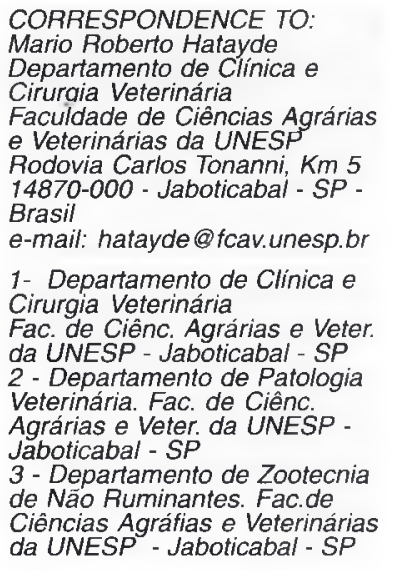

CORRESPONDENCE TO: Mario Roberto Hatayde Departamento de Clínica Faculdade de Ciências Agrárias - Veterinárias da UNESP 14870-000 Brasil

e-mail: hatayde@fcav.unesp.b d UNe Clenc. Agranias e Veter. - Departamento de Patologia Veterinária. Fac. de Ciênc. Agranas e Veter. da UNESP 3 - Departamento de Zootecnia de Năo Ruminantes. Fac.de da UNESP - Jaboticabal - SP

\title{
RESUMO
}

A Crotalaria spectabilis é uma leguminosa amplamente distribuída no Brasil, que pode ser utilizada como adubação verde. Suas sementes podem ser colhidas junto com o milho ou outros grãos quando invade plantações de cereais. Tendo-se em vista que o milho é um componente essencial da ração de aves de exploração comercial, representando aproximadamente $60 \%$ da ração pronta, o presente estudo avaliou a ação tóxica de sementes de Crotalaria spectabilis para aves de corte de linhagem comercial, durante os 28 primeiros dias de vida. Quatro grupos experimentais, subdivididos em grupos de machos e de fêmeas, foram tratados com ração inicial acrescida de sementes de Crotalaria spectabilis trituradas, nas proporções 0,0 (controle), $0,01 \%, 0,1 \%$ e $0,4 \%$. As dietas contendo $0,4 \%$ e $0,1 \%$ provocaram quadro de intoxicação a partir do terceiro dia $(0,4 \%)$ ou da segunda semana $(0,1 \%)$ de vida, provocando sintomas tais como tristeza, apatia, aglomeração, penas arrepiadas, acentuada anorexia e abdômen abaulado. Houve evidente retardo de crescimento e alta mortalidade. Múltiplas lesões foram encontradas: ascite severa; degeneração, necrose, apoptose e proliferação conjuntiva hepáticas, com redução do tamanho do órgão; redução de tecido linfóide da bursa, com presença de células picnóticas; lesões degenerativas em rins; e calcificação intersticial pulmonar, entre outras. As aves controle e aquelas que receberam $0,01 \%$ de sementes não apresentaram alterações patológicas ou de desenvolvimento.

UNITERMOS: Crotalaria spectabilis; Intoxicação alimentar; Galináceos; Leguminosas.

\section{INTRODUÇÃO}

$\mathrm{D}$ entre as plantas que podem causar intoxicação em mamíferos e aves domésticos, encontra-se a Crotalaria spectabilis. O gênero Crotalaria pertence à família Leguminosae, subfamília Papilionoidea, onde existem cerca de 600 espécies, distribuídas em áreas tropicais ${ }^{19}$. Segundo Lorenzi ${ }^{1.3}$ (1991) a Crotalaria spectabilis é amplamente encontrada no território brasileiro, sendo utilizada, em algumas regiões, como adubação verde. Segundo ainda a descrição de Lorenzi ${ }^{13}$ (1991), "é uma planta anual, subarbustiva, ereta, ramificada, glabra, medindo 70 a $100 \mathrm{~cm}$ de altura, com reprodução por sementes. Suas folhas são simples, mucronadas no ápice, glabras na face superior e pubescentes na inferior, com 6 a $12 \mathrm{~cm}$ de comprimento e 2 a $4 \mathrm{~cm}$ de largura, estípulas de 5 a $7 \mathrm{~cm}$ de comprimento. Apresentam flores amarelas, crescem em racemos terminais e axilares de até $30 \mathrm{~cm}$ de comprimento com 20 a 40 flores". As vagens com sementes imaturas são verdes, escurecem gradualmente até tornarem-se pretas quando maduras. As sementes maduras são fïmes, pretas e lustrosas, medem $4 \times 3 \times 2 \mathrm{~mm}$ e pesam 13,8 $\mathrm{mg}$ em média. Os seus princípios tóxicos, os alcalóides pirrolizidínicos, concentram-se nas folhas e sementes. O principal deles, a monocrotalina, foi encontrado na quantidade de $3,98 \%$ do peso seco das semente ${ }^{11.19}$. Existe ainda uma quantidade muito pequena de um outro alcalóide, a espectabilina ${ }^{3}$. Os alcalóides pirrolizidínicos exercem efeitos variados em diferentes espécies de mamíferos, possivelmente em função dos níveis de enzimas microssomais hepáticas ${ }^{15}$. Segundo ainda Panter; James ${ }^{15}(1990)$, bovinos e eqüinos são mais sensíveis aos alcalóides pirrolizidínicos que os ovinos e caprinos, sendo os suínos a espécie mais sensível. Segundo Hooper ${ }^{10}$ (1978), as aves também são muito sensíveis. Estudos relativos aos efeitos dessa planta em aves domésticas descrevem as seguintes manifestações clínicas: inapetência, dispnéia, tremores musculares, incoordenação. depressão, penas eriçadas, pescoço curvado, icterícia, palidez de mucosas e tendência a se agruparem ${ }^{12+80,12}$. Estudos abordando achados patológicos foram ainda realizados por Simpson et al. ${ }^{18}$ (1963), Hooper; Scanlan" (1977), Burguera et al. ${ }^{4}$ (1983), Figueredo et al. $^{7}$ (1987) e Alfonso et al. ${ }^{1}$ ( 1993$)$. Dentre as lesões encontradas por esses autores, destacam-se as localizadas no fígado (hemorragias. alterações degenerativas, necrose de hepatócitos e proliferação conjuntiva), pulmões (edema e enfisema) e rins (edema intersticial, dilatação de cápsula de Bowman) entre outras.

A avicultura brasileira encontra-se entre as principais do mundo. Os cereais são os principais componentes da ração, estando o milho presente em cerca de $60 \%$ do produto final (Embrapa 6 . 1991: Rostagno ${ }^{16}$. 1993). Tendo-se em vista que sementes de Crotalaria spectabilis podem estar presentes no milho e que após a sua trituração fica difícil distingui-las, o presente trabalho foi deli- 
HATAYDE, M.R.; BERCHIERI-JUNIOR, A.; ALESSI, A.C.; CURTARELLI, S.M. Estudo experimental sobre a intoxicação de Gallus gallus domesticus com sementes de ('rotalaria spectabilis. I - Efeito em aves na fase inicial de crescimento. Braz. J. vet. Res. anim. Sei.. São Paulo. v. 34, ก. 6, p. 332-336, 1997

neado para estudar a ação de sementes dessa planta, incorporadas à ração inicial, sobre o desempenho de frangos de corte durante a fase inicial de criação bem como avaliar seus possíveis efeitos patogênicos. Foram avaliados o ganho de peso, o consumo de ração, os sintomas clínicos e os achados patológicos macro e microscópicos.

\section{MATERIAL E MÉTODO}

Foram utilizados 320 pintos de corte, de um dia de idade, da linhagem comercial Hubbard, vacinados contra a doença de Marek Os pintos foram sexados, compondo-se 4 grupos de 40 machos cada (Im, IIm, IIIm, IVm) e 4 grupos de 40 fêmeas cada (If, IIf, IIIf, IVf). O manejo empregado foi o mesmo de granjas comerciais. Utilizou-se ração inicial durante todo o período experimental, ou seja, do primeiro ao $28^{\circ}$ dia de idade das aves. As sementes colhidas, vagens maduras de Crotalaria spectabilis, foram previamente moídas e adicionadas à ração nos seguintes percentuais: grupos ImIf, $0.0 \%$; grupos IIm-IIf, $0.01 \%$; grupos IIIm-IIIf, $0.1 \%$ e grupos IVm-IVf, $0,4 \%$. Essas concentrações foram embasadas nos trabaIhos de Kelly et al. ${ }^{12}$ (1961) e de Harms et al. ${ }^{8}$ (1963). Após a adição das sementes moídas, a ração foi misturada em misturador em "Y", durante 30 minutos

Os diferentes grupos foram mantidos em boxes separados durante todo o período experimental de quatro semanas. Toda ração fornecida foi previamente pesada. Ao final de cada semana, os pintos e as sobras de ração de cada grupo foram pesados. No decorrer do experimento todas as aves que morreram ou apresentaram sintomas clínicos graves, requerendo sacrifício, foram submetidas a exame necroscópico. Ao final do periodo experimental todas as aves foram sacrificadas e submetidas à necropsia. Fragmentos de fígado, rins, pulmão, coração, pâncreas, proventrículo, intestinos e bolsa de Fabricius foram colhidos e fixados para processamento histológico. Para fixação utilizou-se solução de formol a $10 \%$ tamponado com fosfatos ou líquido de Bouin. Depois de fixados, os fragmentos foram desidratados, diafanizados e incluídos em parafina. Cortes de 5 micrômetros de espessura foram obtidos e corados pelo método da hematoxilina e eosina (HE). Alguns cortes foram corados com tricrômio de Gomori para evidenciação de fibras conjuntivas, van Kossa para depósitos de cálcio ou PAS para membranas basais.

Os dados numéricos foram analisados estatisticamente por análise de variância, fazendo-se a comparação das médias pelo teste de Tukey, ao nível de $5 \%$ de probabilidade.

\section{RESULTADOS}

O ganho de peso semanal dos diferentes grupos está ilustrado na Fig. 1. O consumo de ração está ilustrado na Fig. 2.

A partir do terceiro dia de experimento, observou-se que os pintos dos grupos IVm-IVf mostravam sinais de inapetência. Já no final da primeira semana, o desenvolvimento das aves desse grupo estava nitidamente abaixo do dos demais grupos (Fig. 1). Observou-se também menor consumo de ração (Fig. 2) e a morte de um animal. Ao final da segunda semana, a maioria dos animais dos grupos IVm-IVf mostrou sintomas tais como apatia, tristeza, penas arrepiadas, acentuada anorexia, abdômen abaulado e evidente retardo no crescimento, traduzido pelo menor peso médio e por me-

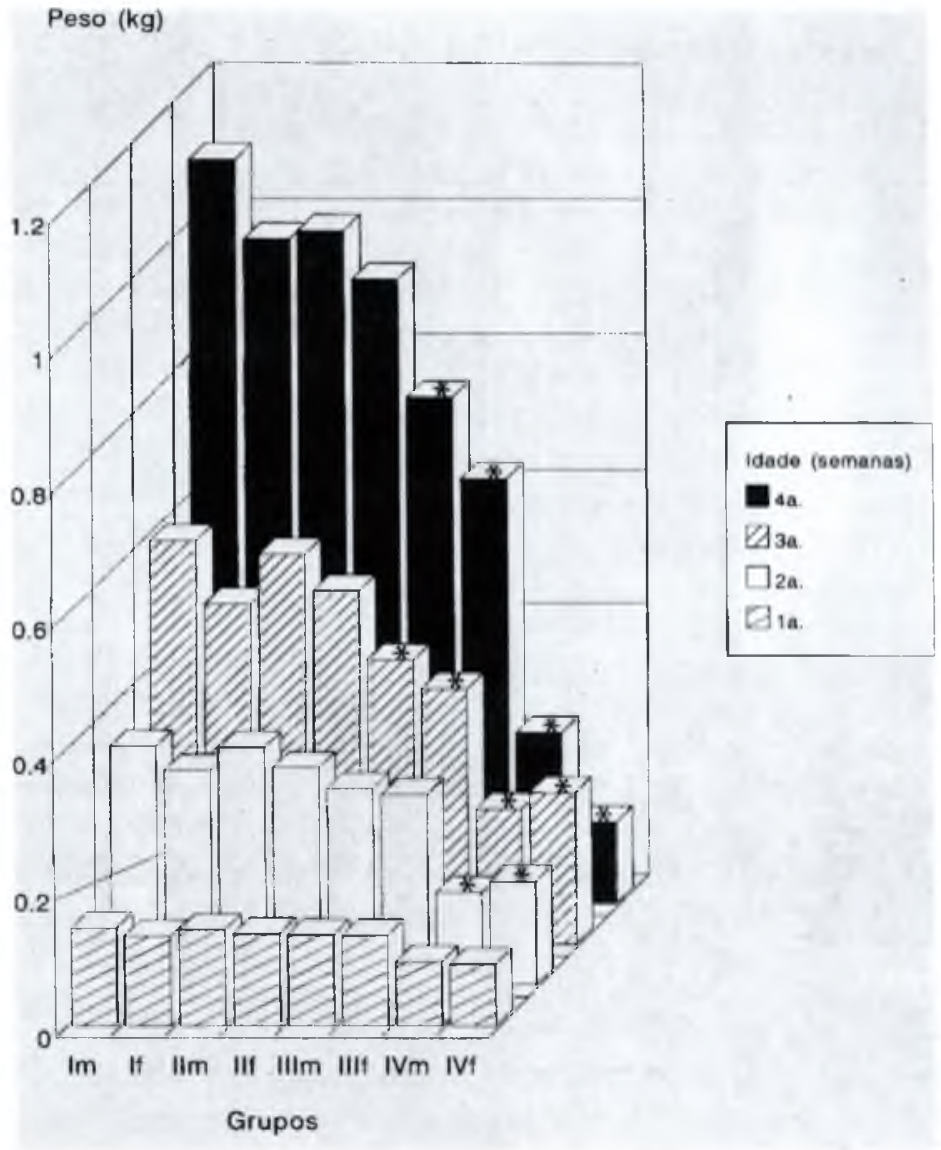

Figura 1

Efeito da administração de sementes de Crotalaria spectabilis na ração de frangos de corte. Grupos Im-If 0,0\%, IIm-IIf 0,01\%, IIIm-IIIf $0,1 \%$ e IVm-IV $0,4 \%$. Ganho de peso dos diferentes grupos nas quatro primeiras semanas de vida. Grupos IIIm-IIIf e IVm-IVf apresentam redução no desenvolvimento $\left({ }^{*} p<0,05\right)$.

nor consumo de ração. Houve morte de dois machos e de 9 fêmeas. Da mesma forma, as aves dos grupos IIIm-IIIf apresentaram queda no consumo de ração e menor peso médio que os grupos Im-If e IIm-IIf. Ao final da terceira semana acentuaram-se as diferenças de peso e consumo de ração entre os grupos III e IV (machos e fêmeas) com relação aos demais. Os sintomas mantiveram-se e agravaram-se até o final da quarta semana. Houve também grande mortalidade de animais dos grupos IVm-IVf $(80 \%$ e $85 \%$ respectivamente). Ao final do experimento, o peso médio das aves dos grupos IVm-IVf foi acentuadamente menor que o peso das aves dos demais grupos (Fig. 1), tendo ocorrido menor consumo (Fig. 2). Da mesma forma, os grupos IIIm-IIIf também apresentaram peso e consumo menores em relação ao controle, sendo que o grupo das fêmeas apresentou diferença mais acentuada. Por outro lado, a diferença observada para os animais dos grupos IIm-IIf em comparação com aqueles do grupo controle não foi significante em relação aos parâmetros ganho de peso, consumo e mortalidade.

No exame necroscópico foram observadas múltiplas lesões, que ocorreram com maior ou menor intensidade em aves dos grupos IIl e IV (machos e fêmeas). Dentre essas, ascite severa e lesões hepáticas foram as que mais chamaram a atenção. O acúmulo de líquido na cavidade abdominal preenchia-a à repleção (Fig. 3). O líquido apresentava-se de coloração amarelada, parcialmente coa- 
HATAYDE, M.R.; BERCHIERI-JUNIOR, A.; ALESSI, A.C.; CURTAREI.LI, S.M. Estudo experimental sobre a intoxicação de Gallus gallus domesticus com sementes de Crotalaria specfabilis. I - Ffeito em aves na fase inicial de crescimento. Braz. J. vet. Res. anim. Sci., São Paulo, v. 34, n. 6, p. 332-336, 1997

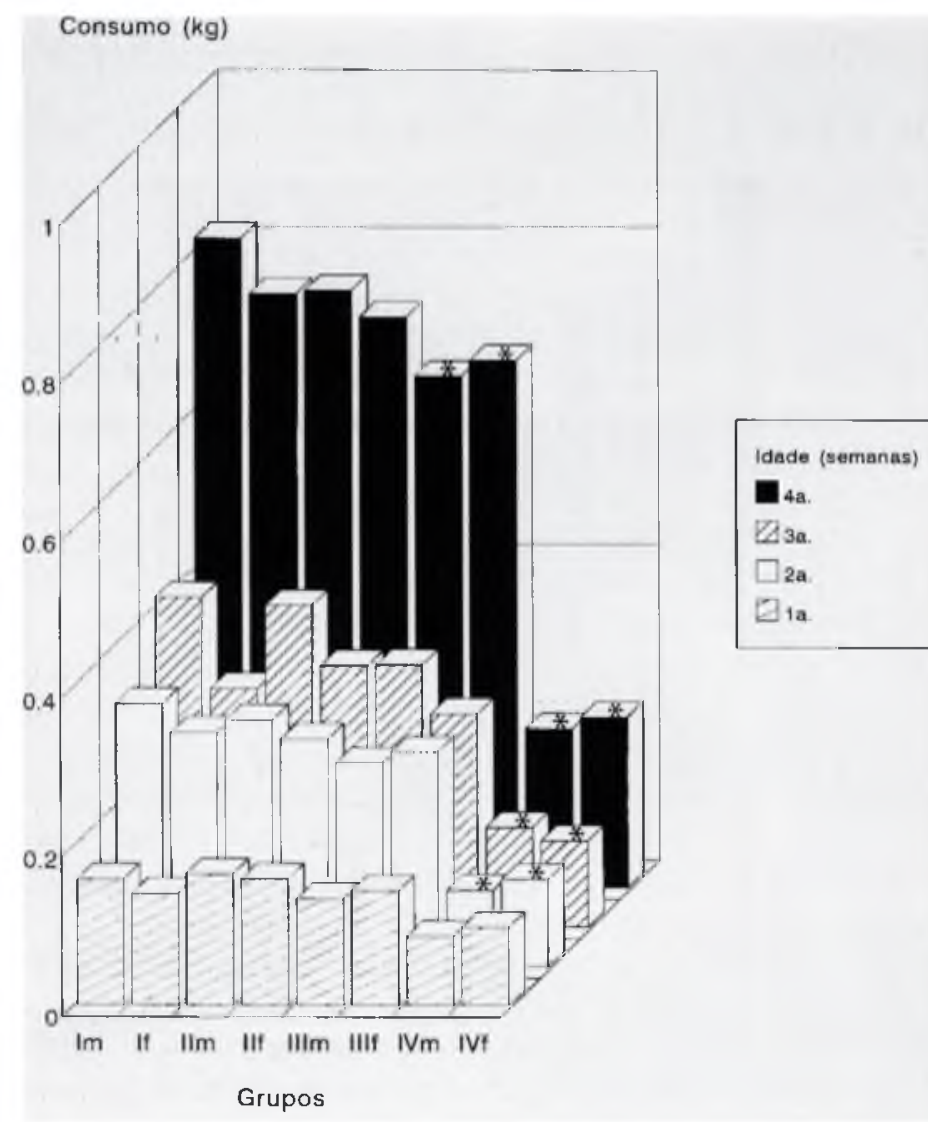

Figura 2

Efeito da administração de sementes de Crotalaria spectabilis na ração de frangos de corte. Grupos Im-If 0,0\%, IIm-IIf 0,01\%, IIIm-IIIf $0,1 \%$ e IVm-IVf $0,4 \%$. Consumo de ração dos diferentes grupos nas primeiras quatro semanas de vida. Grupos IIIm-IIIf e IVm-IVf apresentam redução de consumo $\left({ }^{\star} p<0,05\right)$.

gulado, mas com características de transudado. No presente trabalho, observou-se também que o fígado mostrava-se, nos casos mais graves, muito reduzido de volume (Fig. 4), amarelado, com superfície retraída. Foram observados, ainda, rins aumentados, bursa diminuída de volume (Fig. 4) e líquido espumoso nos pulmões. O exame microscópico revelou, no fígado, apoptose (Fig. 5) e necrose de hepatócitos, esteatose com grandes ou pequenos vacúolos, adensamento de cromatina ao redor da membrana nuclear, nucléolos evidentes e aumentados, proliferação de tecido conjuntivo intersticial, infiltrados focais, difusos ou extensos de células inflamatórias (Fig. 6), principalmente heterófilos. Os rins apresentavam degeneração hidrópica em células epiteliais tubulares, embora não muito acentuada. As bursas de Fabricius apresentavam grande número de células picnóticas, com redução do tecido linfóide. Os pulmões mostraram diversos nódulos ósseos e cartilaginosos ectópicos, evidenciados pela coloração de van Kossa, e edema. Esses nódulos foram raramente encontrados nas aves controle.

As alterações registradas nos grupos IIIm-IIIf e IVm-IVf não se fizeram presentes nas aves dos grupos Im-If e IIm-IIf.

\section{DISCUSSÃO E CONCLUSÕES}

Os efeitos de Crotalaria spectabilis em aves têm sido

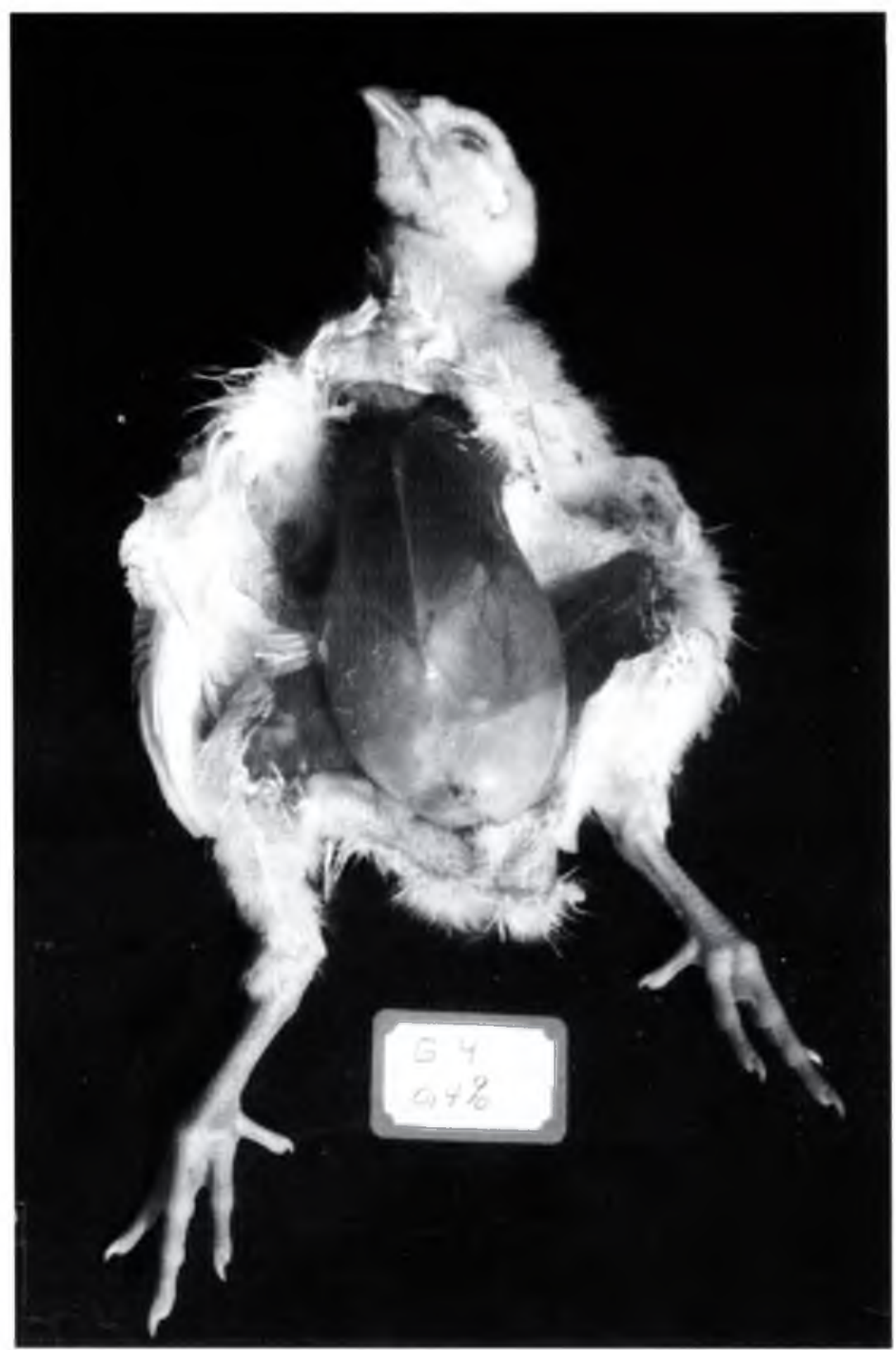

Figura 3

Efeito da administração de sementes de Crotalaria spectabilis na ração de frangos de corte. Pinto tratado com ração contendo $0,4 \%$ de sementes. Observar abdômen abaulado em virtude de ascite.

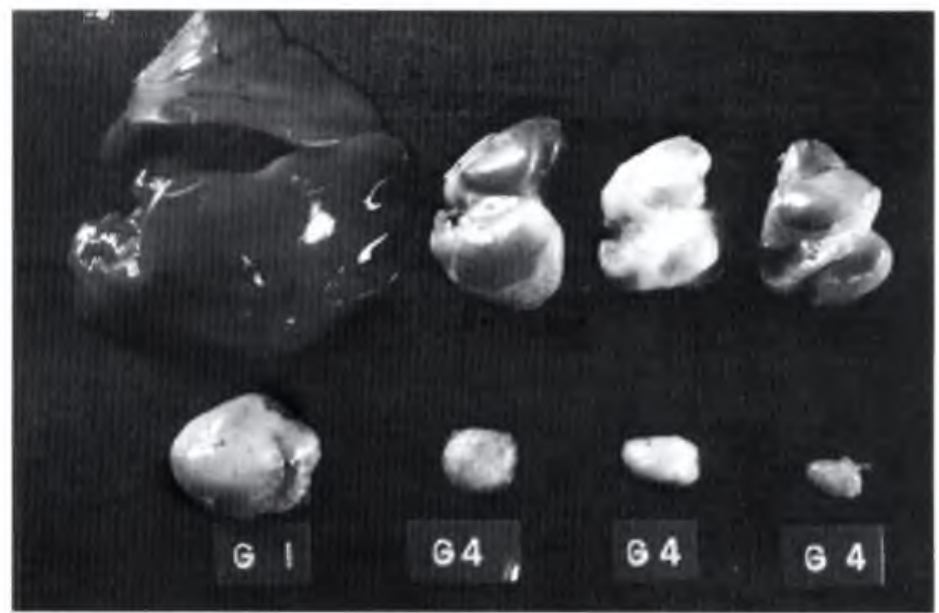

Figura 4

Efeito da administração de sementes de Crotalaria spectabilis na ração de frangos de corte. Fígados e bursas de frangos tratados com $0,0 \%$ (G1-controle) ou com $0,4 \%$ de sementes (G4). Observase drástica redução de volume desses órgãos em aves tratadas. 


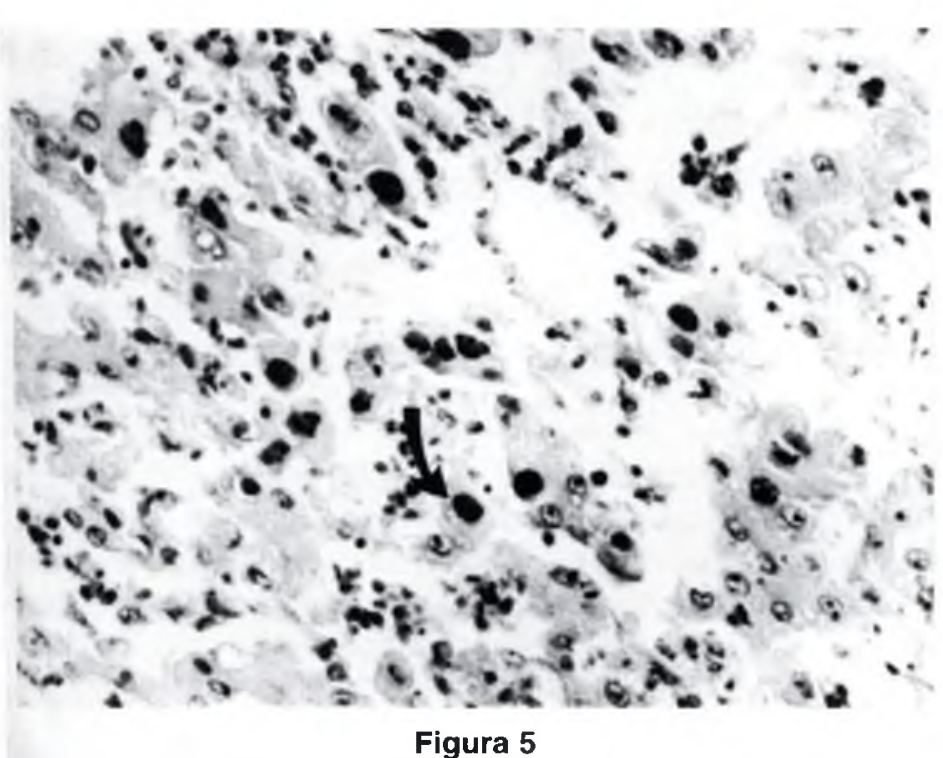

Aspecto microscópico de fígado de frango tratado com ração contendo $0,4 \%$ de sementes de Crotalaria spectabilis. Observar necrose, apoptose (seta) e alterações nucleares de hepatócitos. HE, 400x.

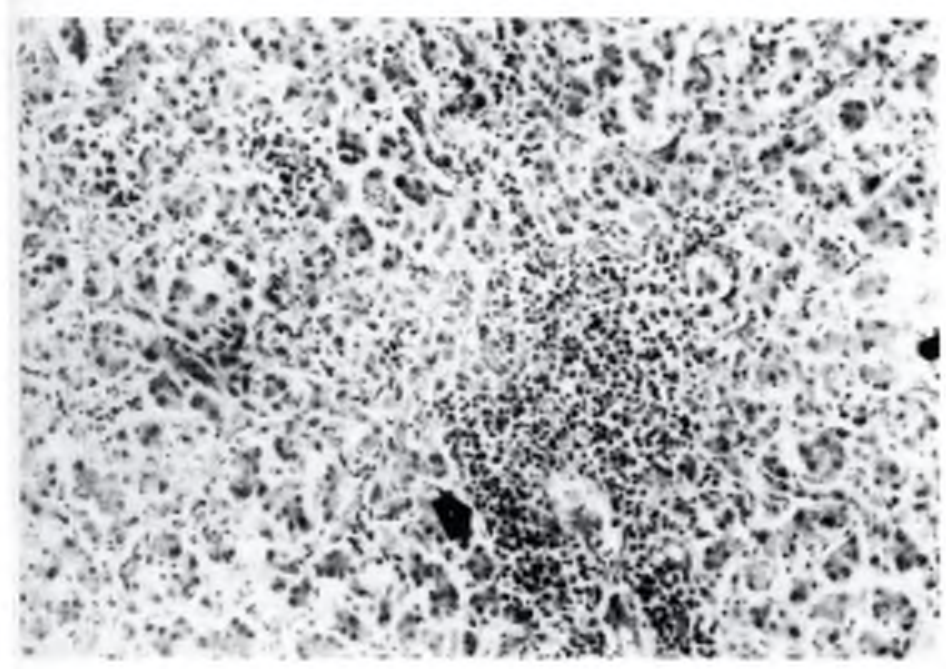

Figura 6

Aspecto microscópico de fígado de frango tratado com ração contendo $0,4 \%$ de sementes de Crotalaria spectabilis. Observar infiltrado difuso de células inflamatórias ao redor de espaço-porta (seta). HE, $200 x$.

descritos na literatura internacional especializada $a^{1,718}$. Na literatura nacional não foram encontrados trabalhos sobre intoxicação por essa planta; por outro lado, considerando-se que a Crotalaria spectabilis pode ser encontrada como invasora em plantações de milho no Brasil, o conhecimento de seu potencial toxigênico tornase de grande importância para a avicultura industrial.

Os resultados da presente pesquisa demonstraram que a presença de sementes de Crotalaria spectabilis na ração, nos níveis de $0,1 \%$ e $0,4 \%$ - grupos III e IV (machos e fêmeas), causa severo quadro de intoxicação nas aves. Os sinais de intoxicação foram mais severos ainda nas aves dos grupos IV, tendo se iniciado já no terceiro dia de vida. Culminou com mortalidade alta $(84 \%)$. De forma semelhante, aves dos gru- pos IIIm-IIIf apresentaram início da sintomatologia de intoxicação um pouco mais tarde, mas com semelhante gravidade. Por outro lado, os grupos IIm-IIf que receberam ração contendo $0,01 \%$ de sementes da planta não apresentaram diferença significante em relação ao grupo controle, ou seja, o ganho de peso e o consumo de ração foram muito próximos aos dos grupos controle (If-Im), dado esse de relevante importância em termos de aplicação prática na avicultura. Vale lembrar que, no presente trabalho, a sexagem dos pintos, com divisão de grupos machos e fêmeas, aumentou a sensibilidade dos resultados, visto que, como é sabido, machos apresentam desenvolvimento superior ao das fêmeas ${ }^{17}$. Dessa forma, foi possível comparar os grupos machos e fêmeas em separado, eliminando-se uma variável externa.

O quadro de sinais e lesões apresentado pelas aves que manifestaram intoxicação revelou uma doença de evolução aguda, com sintomas comuns a várias outras enfermidades. Houve predominância de lesões hepáticas, tanto na observação macro como na microscópica. Além de necrose de hepatócitos e proliferação de tecido conjuntivo, acrescentou-se a observação de ocorrência de apoptose. Em virtude da gravidade das lesões hepáticas, outras alterações foram induzidas, terminando em colapso total do organismo. Deve-se destacar que, dentre os achados de necropsia das aves enfermas, encontrava-se um quadro constante de ascite, quadro esse freqüentemente encontrado em avicultura industrial, para o qual a etiologia ainda não está completamente entendida, sendo apenas associada a distúrbios metabólicos não definidos ${ }^{5}$. A ascite foi observada anteriormente nos trabalhos de Simpson et al. ${ }^{18}(1963)$, onde o líquido não se apresentava coagulado, Burguera et al. ${ }^{4}$ (1983), Figueredo et al. ${ }^{7}$ (1987) e Alfonso et al. ' (1993). Por outro lado, Hooper; Scanlan ${ }^{9}$ (1977) não fizeram referência à presença de ascite no trabalho em que empregaram a Crotalaria retusa na intoxicação experimental de suínos e aves. Em vista dos resultados aqui encontrados, a possibilidade de que Crotalaria spectabilis possa ser uma causa de ascites encontradas a campo deve ser levantada.

Edema pulmonar também foi observado, mas não tão severo quanto o observado nos estudos anteriores, realizados por Burguera et $a l .^{4}$ (1983), Figueredo et al. ${ }^{7}$ (1987) e Alfonso et al. ${ }^{\prime}$ (1993). Por outro lado, diversas aves intoxicadas, portanto com quadro de ascite, mostraram grande número de nódulos ósseos e cartilaginosos no pulmão. Esse tipo de nódulo é achado eventual em pulmão de aves e geralmente não é visto como patológico, no entanto, Maxwell ${ }^{14}$ ( 1988) relata aumento do número desses nódulos em frangos de corte jovens com síndrome ascítica. Este e outros efeitos poderão ser diferentes em aves submetidas à intoxicação quando em idades superiores às das aves aqui utilizadas.

Em conclusão, os resultados do presente trabalho demonstraram que a presença de sementes de Crotalaria spectabilis na dieta das aves em fase inicial de vida, nas concentrações de $0,1 \%$ e $0,4 \%$, é severamente tóxica, provocando quadro grave de lesões que leva a alta taxa de mortalidade, além de redução de ganho de peso. Considerou-se também relevante a presença constante de acentuada ascite. Conclui-se ainda que a presença de sementes em concentração de $0,01 \%$ não altera os parâmetros estudados, pelo menos até o $28^{\circ}$ dia. No entanto, estão em andamento em nosso laboratório experimentos delineados para estudo de exposições mais prolongadas e doses menores. 
HATAYDE, M.R.: BERCIHIERI-JUNIOR, A.; ALESSI, A.C.; CURTARELLI, S.M. Estudo experimental sobre a intoxicação de Gallus gallus domesticus com sementes de Crolaharia spectubilis. I - Efeito em isves nas fase inicial de creseimento. Braz. J. vet. Res. anim. Sci., São Paulo, v. 34, n. 6. p. 332-336. 1967

Agradecimentos a A. J. dos Santos, A. B. Rodrigues, F.A.Ardisson, M.I.Y.Campos, N. B. Tel, E. Homem pelo excelente apoio técnico.

\section{SUMMARY}

Crotalaria spectabilis is a leguminous plant widely distributed in Brazil, sometimes utilized to improve soil. Seeds of Crotalaria spectabilis may be harvested unwillingly together with the grains of corn or other cereals when this plant invades crops. Considering that corn is the main component of poultry rations (about $60 \%$ ), this study was undertaken to investigate the toxic effect of Crotalaria spectabilis seeds added to the ration in commercial broiler, from the one-day-old to the over 28 -dayold birds. Ground seeds were added at different level to the rations: $0.0 \%$ (control), $0.01 \%, 0.1 \%$ and $0.4 \%$. Rations containing $0.4 \%$ and $0.1 \%$ caused symptoms of intoxication, beginning respectively in the third day or during the second week of experiment. Clinical signs included depression, apathy, agglomeration, bristling, anorexia and distended abdomen. The growth was retarded and high mortality occurred during the experiment. Necropsy and histopathological examination revealed prominent ascites and reduction of liver size with degeneration, necrosis and apoptosis of hepatocytes and fibrous connective tissue proliferation. Lymphoid tissue in the bursa was reduced, and picnotic cells were present. Degeneration of tubules of kidneys and interstitial calcification of lungs was also observed. Control poultry and poultry fed with ration containing $0.01 \%$ of seeds showed no relevant alterations.

UNITERMS: Crotalaria spectabilis; Food poisoning; Fowls; Leguminosae.

\section{REFERÊNCIAS BIBLIOGRÁFICAS}

I-ALFONSO, H.A.; FIGUEREDO, M.A; SANCHEZ, L.M.; GOMEZ, B.C. Intoxication due to Crotalaria retusa and Crotalaria spectabilis in chickens and geese. Veterinary and Human Toxicology, v.35, n. 6. p.539, 1993.

2-BIERER, B.W.; VICKERS, C.L.; RHODES, W.H.; THOMAS, J.B. Comparison of the toxic effects of Crotalaria spectabilis and Crotalaria giant striata as complete feed contaminants. Journal of American Veterinary Medical Association, v. 136, n. 7, p. 318-22, 1960

3-BULL, L.B.; CULVENOR, C.C.J.; DICK, A.T. The pyrrolizidine alkaloids: their chemistry, pathogenicity and other biological properties. Amsterdam, NorthHolland, 1968, 293p.

4-BURGUERA, J.A.; EDDS, G.T.; OSUNA, O. Influence of selenium on allatoxin B I or Crolalaria toxicity in turkey poults. American Journal of the Veterinary Research, v. 44 , n. 9, p. 1714-17, 1983

5-COELLO, C.L.: MENOCAL, J.A.: GONZALES, E.A. El sindrome ascitico $\mathrm{cm}$ pollos de engorda. In: CONFERENCIA APINCO 93 DE CIÊNCIA E TECNOLOGIA AVÍCOLA. Santos. 1993. Anais, p.221-48.

6-EMBRAPA. Tahela de composição química e valores encrgéticos de alimentos para suínos e aves. Documento do Centro Nacional de Pesquisa de Suínos e Aves, n. 19,97 p., 1991.

7-FIGUEREDO, M.I.A.; RODRIGUES, J.: ALFONSO, H.A. Patomorfologia de la intoxicacion experimental aguda por Crotalaria retusa y Crotalaria spectabilis en pollos. Revista Culsana de Ciencias Veterinarias, v 18, n. 112, p. 63-71, 1987.

8-HARMS, R.H.; WALDROUP, M.S.; SIMPSON, C.F. Effect of feeding variou: of Crotalaria spectabilis seed on performance of chicks, turkeys, and pullets. Journal of the American Veterinary Medical Association, v. 142, n.3, p. .603.1963.

9-HOOPER, P.T.; SCANI.AN, W.A. Crotalaria retusa poisoning of pigs and poultry Australian Veterinary Journal, v.53, 11. 3, p.109-14, 1977.
10-HOOPER, P.T. Pyrrolizidine alkaloid poisoning with particular reference 10 differences in animal and plant species. In: KEELB, R. F.; VANKAMPEN K. R.: JAMES. L. F. Effects of poisonous plants on livestock. New York. Acadeınic Press, 1978. p.161-76.

11-JOHNSON, A.E.; MOLYNEUX, R.J.; MERRIL, G.B. Chemistry of toxic range plants variation in pyrrolizidine alkaloid content of Senecio, Amsinckia, and Crotalaria species. Journal of Agricultural and Food Chemistry, v.33, n. $50-5,1985$

12-KELLY, J.W.; BARBER, C.W.; PATE, D.D.; HILL, C.H. Effect of feeding Crotalaria seed to young chickens. Journal of the American Veterinary Medical Association, v. 139, n. 11. p.1215-7, 1961

1.3-L ORENZI, H. Plantas daninhas do Brasil: terrestres, aquáticas, parasitas, tóxi cas e medicinais. 2.ed. Nova Odessa, Plantarum, 1991. p.273.

14-MAXWELL. M.H. The histology and ultrastructure of ectopic cartilaginous and osseous nodules in the lungs of young broilers with an ascitic syndrome. Avian Pathology, v.17, n. 1, p.201-19, 1988

15-PANTER, K. E.; JAMES, L. F. Natural plant toxicants in milk: a review. Journal of Animal Science, v. 68, n.3, p. 862-904, 1990

16-ROSTAGNO, H.S. Supercrac - TD software. Viçosa, Universidade Federal de Viçosa. 1993

17-SCOTT, M.L.; NESHEIN, M.C.; YOUNG, R.J. Nutrition of the chicken. 3. ed Ithaca, Cornell University, 1982,562 p.

18-SIMPSON, C. F.; WALDROUP. P. W.; HARMS, R. H. Pathologic changes associated with leeding various levels of Crolalaria spectabilis seed to poultry Journal of the American Veterinary Medical Association, v. 142, n. 3, p $264-71,1963$.

19-WILLIAMS, M.C.; MOLYNEUX, R.J. Occurrence, concentration and toxicity of pyrrolizidine alkaloids in Crotalaria seeds. Weed Science, v. 35, p. 47681,1987

Recebido para publicação: $\quad 27 / 3 / 96$ Aprovado para publicação: 18/2/97 